\title{
Trajetórias profissionais de egressos de mestrados por meio da Cooperação Estruturante em Saúde
}

\author{
Career paths of master's degree graduates in Structural Cooperation in \\ Health
}

\section{Trayectorias profesionales de los estudiantes egresados de la maestría a través de la Cooperación Estructural en Salud}

http://dx.doi.org/10.221713/2358-2332.2016.v14.14001

\begin{abstract}
Alcione Basílio de Abreu, mestre em Saúde Pública pela Escola Nacional de Saúde Pública Sergio Arouca da Fundação Oswaldo Cruz (ENSP-Fiocruz), médico residente em Medicina de Família e Comunidade pela Universidade do Estado do Rio de Janeiro (UERJ), Rio de Janeiro, RJ, Brasil. E-mail: alcionebasilio@gmail.com.
\end{abstract}

Maria Cristina Rodrigues Guilam, doutora em Saúde Coletiva pela Universidade do Estado do Rio de Janeiro (UERJ), coordenadora-geral de Pós-Graduação da Fundação Oswaldo Cruz (Fiocruz). Rio de Janeiro, RJ, Brasil. E-mail: cristina.guilam@gmail.com.

\section{Resumo}

O estudo analisou a trajetória profissional de egressos de mestrados em Saúde Pública e Ciências da Saúde da Fiocruz, ofertados pela cooperação internacional na África. Trata-se de um estudo descritivo e exploratório com os diplomados dos mestrados de Angola e Moçambique, entre os anos de 2006 e 2013. Analisou-se o perfil dos egressos, mapeando suas trajetórias profissionais, suas motivações para escolha da instituição e sua satisfação em relação ao trabalho, por meio de questionário on-line para coleta de dados. Os resultados mostram que os profissionais continuam empregados em instituições públicas, em cargos de pesquisa, docência, coordenação e direção, em seus países de origem, evidenciando que não houve "fuga de cérebro". Esses resultados são relevantes para o ensino superior, pois, nos últimos anos, têm sido investidos recursos significativos para a capacitação de profissionais estrangeiros, por meio da cooperação internacional.

Palavras-chave: Pós-Graduação. Trajetória Profissional. Cooperação Internacional. Cooperação Estruturante em Saúde. África.

\footnotetext{
${ }^{1}$ Como citar: ABNT NBR 6023:2002 e incluir o DOI.
} 
Abreu e Guilam / Trajetórias profissionais de egressos de mestrados por meio da Cooperação Estruturante em Saúde

\begin{abstract}
In this study we analyzed the career path of graduates of the Fundação Oswaldo Cruz Master's Degree in Public Health and Health Sciences, which was offered by the International Cooperation in Africa. This is a descriptive and exploratory study on graduate Master's Degree students from Angola and Mozambique, held between 2006 and 2013. The profile of the graduates was analyzed, taking their career paths, their motivations for choosing that institution and their job satisfaction into consideration. An online questionnaire was used for data collection. The results show that the professionals continue to be employed in public institutions, in positions of research, teaching, coordination and direction, in their countries of origin, providing evidence that there was no 'brain drain'. These results are relevant to higher education, since, in recent years, significant resources have been invested in training foreign professionals through international cooperation.
\end{abstract}

Keywords: Graduate Studies. Career Path. International Cooperation. Structural Cooperation in Health. Africa.

\title{
Resumen
}

Este estudio analiza la trayectoria profesional de los estudiantes egresos de maestrías (ofrecidas por la cooperación internacional en África) en Salud Pública y Ciencias de la Salud de Fiocruz. Se trata de un estudio descriptivo y exploratorio sobre los estudiantes titulados en maestrías en Angola y Mozambique, entre 2006 y 2013. Se analizó el perfil de los titulados y sus carreras profesionales, sus motivaciones para la elección de la institución y su nivel de satisfacción en el trabajo. Además, se utilizó un cuestionario en línea para recopilar datos. Los resultados muestran que estos profesionales siguen trabajando en instituciones públicas, en cargos relacionados con la investigación, docencia, coordinación y dirección en sus países de origen, lo que demuestra que no hubo "fuga de cerebros". Estos resultados son relevantes para la educación superior, ya que en los últimos años se han invertido importantes recursos en la formación de profesionales extranjeros a través de la cooperación internacional.

Palabras clave: Postgrado. Trayectoria Profesional. Cooperación Internacional. Cooperación Estructural en Salud. África.

\section{INTRODUÇÃO}

O desenvolvimento da saúde e da educação nos países pobres continua precário, apesar de todos os avanços sociais conquistados no milênio para superar a pobreza e para promover a inclusão. Nesse contexto, o Brasil tem intensificado, nos últimos anos, os projetos de cooperação internacional (CI), principalmente com os países da África e da América do Sul. A CI é amplamente justificável por ter como alvo os países em que uma significativa parcela da população continua acometida por doenças negligenciadas e já controladas em países desenvolvidos, como tuberculose, hanseníase, malária, parasitoses e outras. 
Abreu e Guilam / Trajetórias profissionais de egressos de mestrados por meio da Cooperação Estruturante em Saúde

Tendo como clientela os profissionais já inseridos nos serviços de saúde, os programas de cooperação para formação de recursos humanos realizados pela Fiocruz na África e América do Sul são inovadores, apresentando como diferencial a oferta de cursos de alto nível de qualidade nos países de origem do aluno, assim, evitando a migração para outros países e fortalecendo instituições locais. Outro diferencial é a organização conjunta do curso com as instituições parceiras, de forma a contemplar necessidades específicas e incluir docentes dos respectivos países.

A CI vem sendo discutida amplamente na literatura científica e sob diversos olhares. O tema é referido tanto como uma "[...] nova configuração de atuação de Estados e organismos internacionais" quanto como "[...] uma alternativa estratégica para o alcance do chamado desenvolvimento" (CAMPOS et al., 2010, p. 170). Portanto, a cooperação entre os países visa melhorar a saúde dos grupos particularmente vulneráveis, mediante o desenvolvimento estruturante dos países parceiros, tendo como alguns de seus objetivos a formação de recursos humanos, o fortalecimento organizacional e o desenvolvimento institucional.

O conceito de Cooperação Estruturante em Saúde (CES) tem como base uma colaboração que vai além da assistência. Suas estratégias incluem criação ou fortalecimento do sistema de saúde dos país parceiros, orientação para elaboração de planejamento estratégico de institutos e ministérios da saúde e formação de recursos humanos estratégicos para o desenvolvimento do país na área. Sua orientação é cooperar, para fortalecer e para construir a autonomia, e propor aos países as condições de se inserirem no contexto global das questões fundamentais da saúde. Nesse sentido, a educação de pós-graduação stricto sensu disposta pela Fiocruz no âmbito da cooperação internacional estruturante é estratégica para o desenvolvimento da saúde global e superação das desigualdades entre países (FUNDAÇÃO OSWALDO CRUZ, 2012).

A Fiocruz é pioneira na oferta de programas de mestrado na África, buscando formar recursos humanos com capacidade de desenvolver pesquisa, ensino e serviços. A instituição desenvolve projetos de CI há algumas décadas, com intensificação a partir de 2007, quando passou a desempenhar o papel de assessora da Comunidade dos Países de Língua Portuguesa (CPLP) na estruturação da cooperação entre os países integrantes da comunidade. Para isso, contou com a inauguração, em outubro de 2008, do Escritório Regional de Representação da Fiocruz na África (Fiocruz África), com sede em Maputo, Moçambique (PASQUALIN, 2014).

Os países da CPLP, em colaboração com a Fiocruz, produziram o Plano Estratégico de Cooperação em Saúde (PECS), incluindo cursos de pós-graduação stricto sensu em Angola e Moçambique, que tem como principal objetivo apoiar o fortalecimento dos sistemas de saúde dos países da comunidade, a partir da criação ou modernização de suas instituições estruturantes (ALMEIDA et al., 2010).

\section{EXPERIÊNCIAS DE MESTRADOS EM ANGOLA E MOÇAMBIQUE}

A Cooperação Estruturante em Saúde desenvolvida pela Fiocruz é uma estratégia inovadora com finalidade de evitar "fugas de cérebros" pelo diferencial de desenvolver os seus cursos nos países de origem dos alunos, por atuar na formação de recursos humanos para a 
Abreu e Guilam / Trajetórias profissionais de egressos de mestrados por meio da Cooperação Estruturante em Saúde

saúde de qualidade, tanto para atuação na prática clínica como no desenvolvimento de pesquisa e docência em países africanos e latino-americanos. A Tabela 1 sintetiza os cursos internacionais a nível stricto sensu, semelhantes aos ofertados regularmente no Brasil, tendo como países contemplados: Angola, Argentina, Moçambique e Peru.

Tabela 1 - Cursos de mestrado acadêmico realizados pela Fiocruz por meio da Cooperação Estruturante em Saúde, com instituições em Angola, Moçambique, Argentina e Peru, 2016

\begin{tabular}{|c|c|c|c|c|c|c|c|c|}
\hline$\frac{n}{\sigma 0}$ & 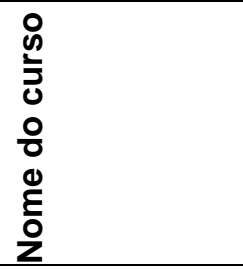 & 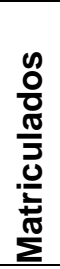 & 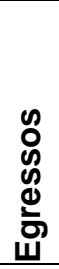 & 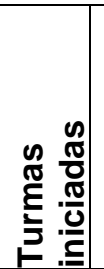 & 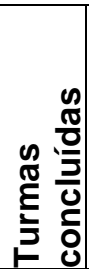 & 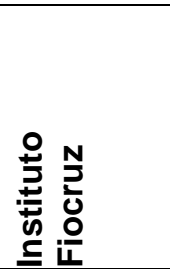 & 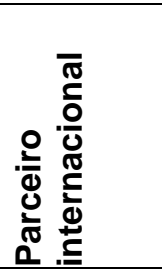 & 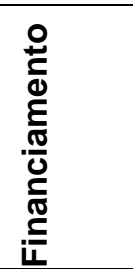 \\
\hline Angola & $\begin{array}{l}\text { Mestrado em } \\
\text { Saúde Pública }\end{array}$ & 30 & 15 & 1 & 1 & $\overline{E N S P}$ & MISAU & $\begin{array}{l}\text { ABC e } \\
\text { Capes }\end{array}$ \\
\hline \multirow[t]{2}{*}{ Argentina } & $\begin{array}{l}\text { Mestrado em } \\
\text { Epidemiologia } \\
\text { em Saúde } \\
\text { Pública }\end{array}$ & 31 & 14 & 2 & 1 & ENSP & \multirow[t]{2}{*}{ ANLIS } & \multirow{2}{*}{$\begin{array}{l}\text { ABC e } \\
\text { Opas }\end{array}$} \\
\hline & $\begin{array}{l}\text { Mestrado em } \\
\text { Biologia } \\
\text { Celular e } \\
\text { Molecular }\end{array}$ & 10 & 9 & 1 & 1 & $\mathrm{IOC}$ & & \\
\hline \multirow[t]{2}{*}{ Moçambique } & $\begin{array}{l}\text { Mestrado em } \\
\text { Ciências da } \\
\text { Saúde }\end{array}$ & 52 & 21 & 4 & 2 & $\mathrm{IOC}$ & INS/Moz & $\begin{array}{l}\text { ABC, } \\
\text { Capes, } \\
\text { Opas e } \\
\text { Fiocruz }\end{array}$ \\
\hline & $\begin{array}{l}\text { Mestrado em } \\
\text { Sistemas de } \\
\text { Saúde }\end{array}$ & 14 & 0 & 1 & 0 & $\begin{array}{l}\text { CPqAM e } \\
\text { ENSP }\end{array}$ & $\begin{array}{l}\text { INS/Moz } \\
\text { e UEM }\end{array}$ & IDRC \\
\hline Peru & $\begin{array}{l}\text { Mestrado em } \\
\text { Saúde Pública }\end{array}$ & 26 & 26 & 1 & 1 & ENSP & INS/Peru & Opas \\
\hline
\end{tabular}

Fonte: Pasqualin (2014).

Legenda: ABC: Agência Brasileira de Cooperação do Ministério das Relações Exteriores; ANLIS: Administracion Nacional de Laboratorios e Institutos de Salud "Dr. Carlos G. Malbran"; CPqAM: Centro de Pesquisa Aggeu Magalhães; INS/Moz: Instituto Nacional de Saúde de Moçambique; INS/Peru: Instituto Nacional de Saúde do Peru; IDRC: International Development Research Centre; OPAS: Organização Pan-Americana de Saúde; UEM: Universidade Eduardo Mondlane.

De acordo com Buss (2011), este novo modelo de cooperação é inovador, pois quebra com o modelo tradicional de transferência unidirecional e passiva de conhecimentos e de tecnologias, integra o desenvolvimento de recursos humanos com o desenvolvimento organizacional e institucional e propõe explorar as capacidades endógenas e recursos existentes em cada país.

A progressão na carreira profissional, além das formas tradicionais de ajuda internacional, está centrada no fortalecimento institucional dos sistemas de saúde dos países 
Abreu e Guilam / Trajetórias profissionais de egressos de mestrados por meio da Cooperação Estruturante em Saúde

parceiros, combinando intervenções concretas com capacidade de construções locais, geração de conhecimentos e promoção do diálogo entre os atores, para que eles possam assumir a liderança nos processos do setor de saúde e formular a agenda para o futuro desenvolvimento da saúde, para que os papéis das organizações internacionais mudem substancialmente.

O curso de mestrado em Saúde Pública em Angola, que teve sua gênese em 2006 como resultado de missões e visitas técnicas anteriores, foi a primeira experiência internacional de apoio à formação stricto sensu da pós-graduação brasileira fora do país, sendo realizado no âmbito de um projeto de cooperação técnica do Governo Brasileiro com os Países Africanos de Língua Oficial Portuguesa (PALOP) e posteriormente inserido em um projeto mais amplo de cooperação Brasil-Angola (PASQUALIN, 2014).

Tendo como base legal a existência de um acordo de cooperação econômica, científica e técnica entre o Governo da República Federativa do Brasil e o Governo da República Popular de Angola, assinado em 11 de junho de 1980 e promulgado em 5 de outubro de 1990, o curso é fruto de um ajuste complementar ao acordo, firmado com o Ministério de Saúde angolano, em julho de 2007, e intitulado Formação de docentes em Saúde Pública em Angola (ARTMANN, 2012). Os elementos estruturantes, além do apoio à implantação da Escola Nacional de Saúde Pública de Angola (ENSPA), previam a formação de recursos humanos em saúde, a qual se comprometia com a pesquisa e com a capacitação para transformação das práticas em saúde (TELLES, 2014).

Ainda que, nos últimos anos, a internacionalização na pós-graduação tenha se intensificado e se diversificado, e que novas estratégias estejam em pauta para fomentar a aproximação entre pesquisadores (LEITE; CARMO, 2014), a viabilização do tipo de cooperação realizada pela Fiocruz foi uma novidade para as instituições envolvidas, gerando grandes desafios a serem superados por gestores, docentes e discentes, durante todo o processo de implantação e execução do curso.

O mestrado, que atendia a uma demanda do Ministério da Saúde de Angola para consolidação do sistema de saúde nacional e para capacitação dos quadros estratégicos da futura ENSPA, tinha como objetivo contribuir para o aprimoramento e para o desenvolvimento do sistema de saúde e qualificar os profissionais para a análise, planejamento, desenvolvimento e avaliação de políticas de saúde, no contexto epidemiológico e social do país (PASQUALIN, 2014).

Com financiamento da Capes e da Agência Brasileira de Cooperação do Ministério das Relações Exteriores (ABC/MRE), a gestão dos recursos foi feita pela Vice-Presidência de Educação, Informação e Comunicação (VPEIC) da Fiocruz, tendo o Governo de Angola arcado com o transporte interno dos docentes e coordenação durante os módulos e orientações no país.

O público-alvo do programa, de natureza multiprofissional, foi composto por profissionais de nível superior dos quadros do Ministério da Saúde de Angola, da Universidade Agostinho Neto (UAN) e das suas direções de saúde das províncias. Inicialmente foi prevista a oferta de 25 vagas, sendo 20 para Angola e cinco para Cabo Verde, Guiné-Bissau, Moçambique e São Tomé e Príncipe. Em caso de não preenchimento das cinco vagas dos outros países dos PALOP, estas seriam revertidas para Angola, como de fato ocorreu, inclusive com expansão para 30 matriculados após a seleção realizada no primeiro semestre de 2007. 
Abreu e Guilam / Trajetórias profissionais de egressos de mestrados por meio da Cooperação Estruturante em Saúde

O curso teve início em maio de 2007, nas dependências do Instituto Superior de Enfermagem da UAN, em Angola, e seu planejamento previa aulas concentradas em duas semanas e apoio de um ambiente virtual. Entraves de diversas naturezas dificultaram o bom andamento do curso: a precarização dos espaços físicos, os problemas com transportes, os alojamentos (dos docentes) com infraestrutura inadequada e a indisponibilidade de internet. $\mathrm{O}$ projeto previa um período de mobilidade na Fiocruz por quatro meses, o que também não foi possível. Somaram-se as dificuldades logísticas e as questões de ordem política, como a eleição no país. Todos esses fatores exigiram a revisão do projeto inicial e negociações com os órgãos financiadores e executores.

O processo de negociação, a revisão do cronograma e as estratégias de continuidade levaram a uma paralisação do curso por um ano. No retorno, em 2010, após aulas de recuperação e os seminários de metodologia da pesquisa, a coordenação e o colegiado do curso definiram que parte dos alunos (15) seriam desligados e receberiam um certificado de conclusão das disciplinas.

Com a revisão do planejamento, os demais participaram de dois seminários no Brasil e tiveram, ainda, a possibilidade de cursar disciplinas na Escola Nacional de Saúde Pública (ENSP). As defesas também foram realizadas na ENSP no período de 2010 a 2011.

No I Seminário Angola-Brasil de Saúde Pública, realizado em maio de 2012, houve a publicação de 15 resumos referentes às dissertações defendidas nos cursos ofertados pela

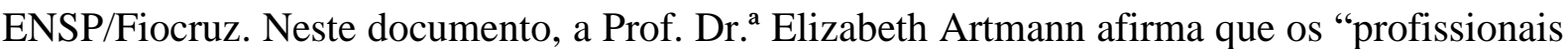
estão aptos para assumir novas responsabilidades, seja em termos de docência em saúde pública, seja na coordenação de pesquisa" (ARTMANN, 2012).

O acordo geral de cooperação entre o Governo da República de Moçambique, firmado em 1981, é a base legal para o Projeto de Fortalecimento do Instituto Nacional de Saúde de Moçambique. Após a assinatura de um termo de ajuste complementar, assinado em 2007, foi criado o Curso de Mestrado em Ciências da Saúde, coordenado pelo Instituto Oswaldo Cruz (IOC) e amplamente discutido com o INS, para que seu conteúdo contemplasse as necessidades do país.

Em março de 2008, iniciou-se a primeira turma, financiada pela ABC/MRE e pela Capes, tendo como ênfase o diagnóstico molecular e imunopatogenia de doenças infecciosas. O curso, de natureza interdisciplinar e multiprofissional, tem por objetivo a formação dos funcionários ligados a laboratórios ou a pesquisas do INS, graduados nas áreas das Ciências Biomédicas, que tiverem parecer favorável de suas chefias para liberação do trabalho e se comprometem a ficar cinco anos trabalhando para o sistema nacional de saúde.

O programa previa os seguintes compromissos: oferecer um orientador brasileiro e um moçambicano; fomentar parceria entre os pesquisadores dos dois países; disponibilizar um período de mobilidade de dois a três meses no Brasil por aluno; ofertar disciplinas ministradas por parcerias de professores brasileiros e moçambicanos; instalar bancas de qualificação e defesa de tese em Maputo, com participação de membros moçambicanos; e titular os alunos pelo Instituto Oswaldo Cruz.

Embora algumas dificuldades identificadas em Angola também tenham surgido em Moçambique, a coordenação do curso considerou que as questões foram ultrapassadas e a 
Abreu e Guilam / Trajetórias profissionais de egressos de mestrados por meio da Cooperação Estruturante em Saúde

grande maioria dos mestrandos chegou ao fim do curso, com sucesso. As questões ultrapassadas foram percalços de infraestrutura, barreiras geográficas, questões burocráticas que atrasam as liberações das bolsas, não disponibilidade de alojamentos no Brasil e problemas com a manutenção do financiamento do professor em Maputo. Estes fatores não foram impeditivos para a realização de dissertações de elevada qualidade acadêmica, visto que foi perceptível o alto grau de comprometimento de docentes e discentes.

Ao longo de nove anos de parceria, o IOC formou 40 mestres, consequentemente, ampliou e fortaleceu o quadro de pesquisadores do INS. Alguns egressos passaram a ocupar posições de liderança na instituição, bem como foram capacitados a exercer a função de orientação. Assim, em 2014, foi feita a primeira seleção para uma turma de doutorado em Ciências da Saúde em Moçambique.

O foco desse estudo foi a trajetória dos egressos em dois cursos, o primeiro, em Angola, coordenado pelo Programa de Pós-Graduação em Saúde Pública da Escola Nacional de Saúde Pública, e o segundo por um consórcio de três programas do Instituto Oswaldo Cruz: Biologia Parasitária; Biologia Celular e Molecular; e Medicina Tropical.

\section{MÉTODOS ADOTADOS PARA O ESTUDO}

Trata-se de uma pesquisa de natureza descritiva e exploratória. Descritiva, pois tem por objetivo detalhar as características de determinada população - os alunos dos cursos da Fiocruz oferecidos na África - e exploratória, pois tem como principal finalidade a formulação de problemas mais precisos ou hipóteses pesquisáveis em estudos posteriores. (GIL, 2008)

Nesse sentido, discutimos a importância da cooperação internacional para formação de recursos humanos na África, apresentamos o perfil dos egressos e sua trajetória após a conclusão do curso e consideramos que a avaliação de resultados da CI é um processo cuja compreensão demanda pesquisas aprofundadas em futuros trabalhos.

As informações referentes às trajetórias profissionais foram coletadas no Sistema de Gerenciamento Acadêmico Eletrônico (Siga) da Fiocruz e nos questionários on-line respondidos pelos trabalhadores egressos.

A população de estudo foi constituída por 36 trabalhadores egressos dos mestrados da Fiocruz em Angola e Moçambique, por meio da CES, no período 2008 a 2013. Não foram incluídos os alunos africanos que fizeram o curso no Brasil, por meio do programa PEC-PG.

O procedimento de coleta de dados foi realizado em quatro etapas. A primeira etapa foi um levantamento no Siga Fiocruz, autorizado por um termo de anuência, para verificação do nome completo dos egressos, o país de origem, sexo, idade, graduação, titulação, turma, ano de conclusão, e-mail e endereço. A segunda etapa foi a elaboração de um questionário baseado em dois modelos de projetos de acompanhamento de egressos da Fiocruz, sendo o primeiro desenvolvido por Elizabeth Artmann e Claudio Huquet entre 1998 e 2002, e o segundo, por Virgínia Alonso Hortale et al. entre 2007 e 2010 (HORTALE et al., 2014). O roteiro do questionário abordou os aspectos: atividade profissional, satisfação profissional e processo de trabalho. A terceira etapa foi um teste piloto que possibilitou a melhora do questionário, mediante a troca de expressões e exclusão de perguntas inadequadas aos objetivos 
Abreu e Guilam / Trajetórias profissionais de egressos de mestrados por meio da Cooperação Estruturante em Saúde

estabelecidos. A quarta etapa foi o contato por meio de e-mail, com os egressos encontrados no Siga.

O texto do e-mail, enviado aos egressos, explicava o estudo e apresentava um link de acesso ao questionário com o Termo de Consentimento Livre e Esclarecido, oferendo ao egresso as opções de recusar ou aceitar participar da pesquisa. Foram feitas três tentativas com 15 dias de intervalos entre elas, após o envio do primeiro e-mail. Os dados foram transferidos para uma planilha do Excel. As perguntas do questionário foram analisadas por meio de técnicas estatísticas básicas, utilizando frequências e percentuais. Para a avaliação da percepção dos respondentes, quanto à satisfação profissional e ao grau de impacto do mestrado, foi utilizada a escala Likert de três e cinco pontos.

\section{RESULTADOS E DISCUSSÃO}

A taxa geral de retorno do questionário foi de $47,2 \%$ de 36 , acima do obtido em estudos similares (LAKATOS; MARCONI, 2010). Em relação ao perfil sociodemográfico, foram analisadas as variáveis: sexo, idade, estado e província de residência. Dos 36 trabalhadores egressos, 55,6 \% são homens. Moçambique teve uma proporção de 52,4\% de mulheres egressas, e de 47,6\% de homens. Angola teve maior porcentagem de homens (66,6\%). Esse aspecto pode ser explicado, pois os homens, em Angola, ocupam a maioria dos postos de trabalhos de níveis técnicos e superiores (KLAVEREN et al., 2009).

Dos 15 egressos de Angola, 53,3\% tinham idades entre 36 a 45 anos, e $40 \%$ entre 46 a 55 anos. Quanto aos 21 egressos de Moçambique, 71,4\% tinham entre 26 a 35 anos, e 28,6\% entre 36 a 45 anos ao concluir o curso de mestrado.

Em relação ao estado da Federação e províncias, em que os egressos dos cursos de mestrado nasceram e residem, dos egressos de Angola, todos nasceram no país e residem no mesmo local, sendo 13 na capital Luanda, um na província de Bendina e um na província de Namibe. Dos egressos de Moçambique, todos são naturais do país e a maioria (19) reside na capital Maputo, seguido por 1 na província de Martinica e 1 na província de Matola.

A situação acadêmica foi caracterizada quanto aos cursos de graduação, rede pública ou privada, estados e províncias das faculdades cursadas. Dos egressos de Angola, 53\% mencionaram serem formados em enfermagem, enquanto $47 \%$ em outros cursos, como Medicina, Psicologia, Farmácia e Ciência Hospitalar. Como o mestrado em Saúde Pública teve natureza multidisciplinar, o público alvo-foi constituído por graduados das várias áreas da saúde.

Dos egressos de Moçambique, $80 \%$ são de Ciências Biológicas e os 20\% restantes formados em Medicina Veterinária, Medicina e Bioquímica. O curso de mestrado em Ciências da Saúde, também tem cunho multidisciplinar com grande ênfase em práticas laboratoriais, atraindo provavelmente um número maior de formados em Ciências Biológicas.

Cem por cento dos egressos de Moçambique são provenientes de universidades de natureza pública. Já entre os egressos de Angola, 86\% são provenientes de universidades de natureza pública e $14 \%$ provenientes de instituições privadas de ensino.

Do total de faculdades mencionadas pelos egressos de Angola, 60\% delas estão na capital, Luanda, enquanto $40 \%$ estão em outros países estrangeiros, com predominância por 
Abreu e Guilam / Trajetórias profissionais de egressos de mestrados por meio da Cooperação Estruturante em Saúde

países da África e da Ásia, entre eles, Minsk, na Bielorrússia, Katanga, no Congo, São Paulo, no Brasil, e Tashkent, no Uzbequistão, São Petersburgo, na Rússia, e Kharkov, na Ucrânia. Já entre as faculdades mencionadas pelos egressos de Moçambique, $95 \%$ delas estão em seu país de origem, na capital, Maputo, e apenas 5\% em outros países, como Córdoba, na Argentina.

A situação profissional foi um eixo de bastante importância para a pesquisa por caracterizar a situação de emprego dos egressos. Foram analisados os aspectos: situação atual de atividade, natureza da instituição de trabalho, ano de ingresso na instituição, posição ocupada e carga horária semanal.

Em relação à principal atividade profissional, definida como a atividade de maior carga horária exercida pelos egressos, atualmente, a maioria permaneceu com vínculo empregatício nos países de origem, em instituições públicas. Hortale et al. (2014), em estudo com egressos do doutorado da Fiocruz, constataram que o vínculo com instituição pública também foi mais frequente e crescente ao longo do tempo.

Antes de ingressar no curso de mestrado, 91,7\% dos trabalhadores de Moçambique exerciam atividade profissional na mesma instituição que trabalham atualmente. Já os egressos de Angola, $60 \%$ não exerciam atividade profissional na instituição que trabalham atualmente, porém permaneceram em seus países de origem. Isso demonstra que os egressos permaneceram próximos dos locais onde realizaram os cursos de mestrado e não tiveram necessidade de deslocamento para cidades com maior conglomerado de serviços e oportunidades de trabalho.

Evitar a "fuga cérebros" é uma questão central para as instituições africanas. Kellerman et al. (2012), em pesquisa com egressos de um Mestrado em Epidemiologia ofertado na África, identificaram um percentual de migração de 19\% após a conclusão do curso. Segundo Pezzoli et al. (2015), manter os egressos em seus países de origem após a conclusão do mestrado tem sido um dos grandes desafios, especialmente por causa da baixa remuneração dos países da África que oferecem menos oportunidades profissionais do que os países europeus.

Em relação ao ano de ingresso na instituição atual, os egressos de Angola estão há mais tempo na instituição em que trabalham, pois ingressaram a partir de 1980. Em contrapartida, a maioria dos egressos de Moçambique estão nas instituições em que trabalham por volta de 10 anos, pois ingressaram a partir de 2005.

Um dos impactos do curso foi a progressão em relação à posição profissional ocupada anteriormente. Houve uma predominância de cargos elevados tanto entre os egressos de Angola, quanto entre os egressos de Moçambique. Nos dois países, os egressos responderam que passaram a ocupar cargos de chefia, direção e secretaria de Estado, além de exercerem função de gestores de programas de saúde e docência.

No que diz respeito aos tipos de atividades que desempenham, $80 \%$ dos respondentes de Angola referiram exercer atividades profissionais simultâneas, entre elas, $80 \%$ estão envolvidas com ensino; $80 \%$ com assistência à saúde; seguido por $60 \%$ com pesquisa, e $40 \%$ com desenvolvimento tecnológico. Alguns poucos egressos, em torno de 20\%, atuam na área de gestão acadêmica, consultoria ou em ambas. Já em relação aos respondentes de Moçambique, somente 50\% referiram exercer atividades profissionais simultâneas, sendo $80,3 \%$ envolvidos com pesquisa; $66,7 \%$ com ensino; seguidos por $33,3 \%$ com desenvolvimento tecnológico e $25 \%$ com assistência à saúde. A função pesquisador foi predominante entre os 
Abreu e Guilam / Trajetórias profissionais de egressos de mestrados por meio da Cooperação Estruturante em Saúde

respondentes Moçambicanos. Já entre respondentes Angolanos não houve uma função predominante.

Em relação à carga horária semanal de trabalho, entre os egressos de Angola, 80\% trabalham mais de 40 horas semanais, enquanto $20 \%$ trabalham de 31 a 40 horas semanais. Dos egressos de Moçambique, 33,3\% trabalham entre 31 a 40 horas semanais, enquanto 66,7\% trabalham mais de 40 horas semanais.

A satisfação profissional foi analisada por meio da utilização da escala de valores Likert. A maioria dos egressos, dos dois grupos estudados, referiram que estão "satisfeitos" ou "extremamente satisfeitos". Apontaram como maiores proporções de satisfação, os itens como "relevância social do trabalho", "oportunidade de novas aprendizagens e exercício da criatividade", "oportunidade de desenvolvimento profissional", "carga de trabalho", "autonomia", "prestígio" e "relações de trabalho". Com relação ao atributo "remuneração", observamos que os dois grupos estudados ficaram insatisfeitos, o que pode evidenciar uma desvalorização profissional, mesmo com um título de mestrado. O cálculo dos intervalos de confiança (IC 95\%) para as proporções desses atributos não apontaram diferenças (Gráfico 1).

\title{
Gráfico 1 - Grau de satisfação profisssional dos egressos de Angola e Moçambique para diferentes atributos
}

\author{
Satisfação profissional \\ Satisfação Alta - Angola: 4,025 Moçambique: 3,427 \\ Teste U Mann Whitney (P-valor): 0,1343
}

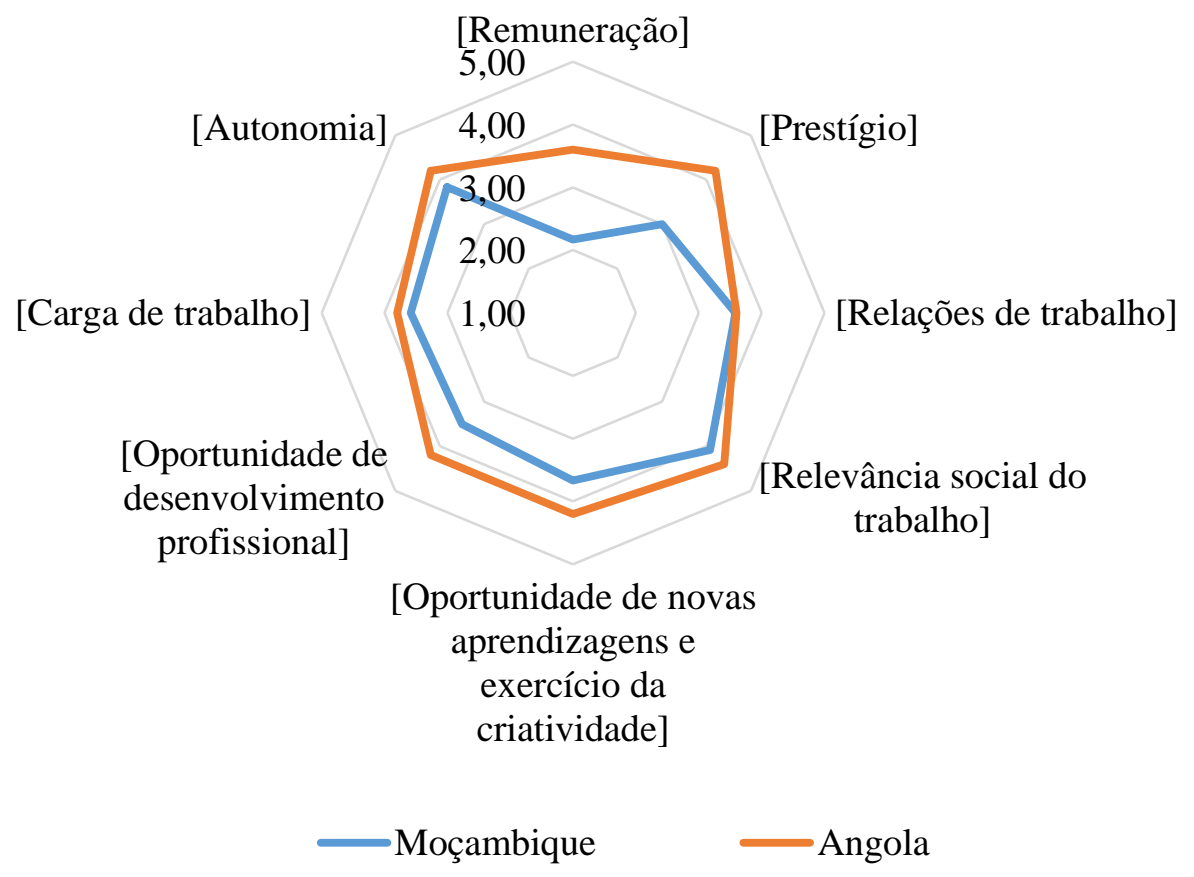

Fonte: Elaborado pelos autores.

Os respondentes avaliaram cinco atributos acerca das contribuições do mestrado nas atividades que desenvolvem atualmente. Foi elevado, entre os dois grupos de egressos 
Abreu e Guilam / Trajetórias profissionais de egressos de mestrados por meio da Cooperação Estruturante em Saúde

estudados, o percentual que avaliou como "alto" o grau de impacto do mestrado na vida profissional. Dos egressos de Angola, quatro avaliaram como "alto" e um como "médio" o grau de impacto do mestrado na vida profissional. Já entre os egressos de Moçambique 43\% avaliaram como "alto"; $38 \%$ como "médio" e 19\% como "baixo" o grau de impacto do mestrado na vida profissional (Gráfico 2).

\section{Gráfico 2 - Grau de impacto do mestrado na vida profissional}

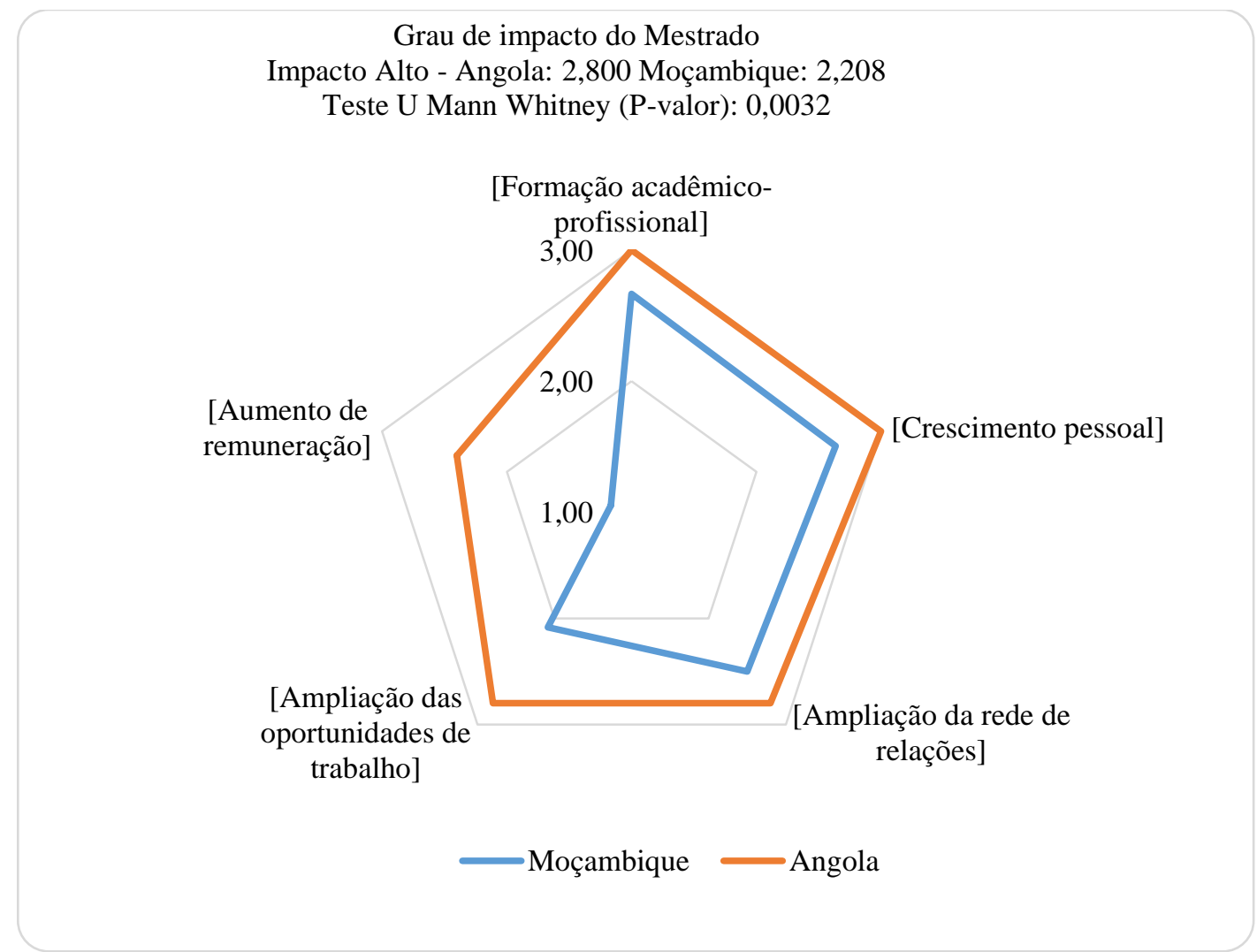

Fonte: Elaborado pelos autores.

Tanto os egressos de Angola, quanto os egressos de Moçambique apontaram os atributos "formação acadêmico-profissional", "crescimento pessoal" e "ampliação da rede de relações" como "alto impacto". Houve diferenças entre os dois grupos estudados, em relação aos atributos "ampliação das oportunidades de trabalho" e "aumento de remuneração", que foram avaliados como "alto impacto" entre os egressos de Angola e "médio impacto" e "baixo impacto" entre os egressos de Moçambique. Vale ressaltar que $83.3 \%$ dos egressos de Moçambique consideram que o curso não resultou em alterações do nível de remuneração, pois não tiveram aumento de salários.

Segundo Hortale et al. (2010), em estudo sobre os egressos dos mestrados profissionais da Fiocruz na área da Saúde, cerca de $60 \%$ dos egressos consideraram que o curso possibilitou adquirir conhecimentos, capacitando-os a desenvolver propostas para realizarem intervenções em suas práticas de trabalhos, assim como relatam a importância do mestrado na produção de mudanças positivas em seus processos de trabalhos. 
Abreu e Guilam / Trajetórias profissionais de egressos de mestrados por meio da Cooperação Estruturante em Saúde

Analisando as evidências do grau em que os mestrados produziram modificações no modo como os egressos desenvolvem suas atividades de trabalho, os dois grupos de egressos consideram que os cursos contribuíram substancialmente. Dos egressos de Angola, 100\% consideram que o curso contribuiu muito positivamente, enquanto entre os egressos de Moçambique, $58.3 \%$ consideram positivamente e $41.7 \%$ consideram muito positivamente.

Os cursos de mestrado, ofertados em Angola e Moçambique pela Fiocruz, estão diretamente ligados aos serviços de saúde, assim os egressos, durante e após a conclusão do curso, são estimulados a perceber a possibilidade de mudanças nas práticas de trabalho no seu contexto e com isso realizá-las.

No que diz respeito à motivação dos egressos para a realização do mestrado, apesar de alguns trabalhadores terem a Fiocruz como única opção para ingressar no mestrado, devido à escassez de cursos stricto sensu na África, destacou-se o atributo "excelência do curso", que apresentou percentual de $100 \%$ entre os egressos de Angola, seguidos pelos atributos "prestígio da instituição" com 80\%, "tradição da instituição" com 40 \%, e "probabilidade alta de obter bolsa de estudos" e "conveniência decorrente da estruturação do curso" com $20 \%$ cada.

Entre os egressos de Moçambique, o atributo de maior proporção foi "tradição da instituição" com 66,7\%, seguido de "prestígio da instituição" e "excelência do curso", com 50\% cada, seguidos pelos atributos "Interesse na linha de pesquisa oferecida" e "probabilidade alta de obter bolsa de estudos", que apresentaram percentual de 16,7\%, "conveniência decorrente da estruturação do curso" e "interesse num orientador específico" apresentaram percentual de $8,3 \%$.

Resultados semelhantes foram relatados por Gomes e Goldenberg (2010), que observaram a concordância entre os egressos sobre os motivos da escolha das instituições formadoras, como tradição, prestígio, excelência da instituição e linha de pesquisa. Segundo os autores, apesar de grande parte dos egressos já estar inserida no mercado de trabalho e desenvolvendo atividades profissionais na própria instituição, foi grande a porcentagem que assinalou "possibilidade de obtenção de bolsa de estudo", "interesse por um orientador específico" e "estruturação do curso".

\section{CONSIDERAÇÕES FINAIS}

Pesquisas de egressos constituem item fundamental para a avaliação de processos formativos. No caso desta pesquisa, a trajetória dos egressos permite não só avaliar a qualidade do curso, mas também entender até que ponto a Cooperação Estruturante em Saúde está cumprindo seu papel.

O desenvolvimento desta pesquisa possibilitou uma análise de como os cursos de Mestrado em Saúde Pública de Angola e de Ciências da Saúde de Moçambique, ofertados pela Fiocruz mediante a CES, provocaram mudanças nas trajetórias profissionais dos egressos. A pesquisa possibilitou conhecer as contribuições dos cursos para a formação profissional, sob seus pontos de vista, além da caracterização do perfil sociodemográfico desses trabalhadores.

De um modo geral, os egressos relataram que os cursos de mestrado ocasionaram impactos positivos nas suas trajetórias profissionais. A maioria dos egressos relatou que teve maiores oportunidades ao buscar um novo emprego, em adquirir promoção no trabalho 
Abreu e Guilam / Trajetórias profissionais de egressos de mestrados por meio da Cooperação Estruturante em Saúde

mediante mudanças de cargo ou função, além da oportunidade de desenvolvimento de novas habilidades, como a gestão à docência e à pesquisa.

Nesse sentido, os mestrados da Fiocruz na África, por serem multiprofissionais, com ênfase na aprendizagem e produção de pesquisas baseadas nas necessidades das comunidades, favorecem aos egressos uma compreensão prática dos sistemas de saúde e os preparam para trabalhar como profissionais de saúde pública e ciências da saúde em suas cidades de origem. Também os capacitam adequadamente para trabalhar como professores, assim com pesquisadores e gestores.

Os resultados desse estudo poderão ser usados por instituições brasileiras para compreender melhor quais são os impactos que os cursos causam na trajetória profissional e nos processos de trabalho dos profissionais estrangeiros, para, assim, avaliar os programas existentes e para auxiliar o desenvolvimento de futuras Cooperações Internacionais.

Consideramos que os objetivos da Fiocruz de melhorar o nível de educação em Saúde Pública e Ciências da Saúde nos países da CPLP vem sendo alcançados, pois os cursos têm contribuído para o processo de qualificação de profissionais competentes e bem treinados em Saúde Pública e Ciências da Saúde, além de formar pesquisadores, professores e líderes.

Esses resultados são relevantes para o ensino superior, pois nos últimos anos têm sido investidos recursos significativos para a ampliação do número de vagas para profissionais estrangeiros, tal como evidenciado pelo número crescente de programas e de instituições que

participam da cooperação internacional. É essencial que os líderes do ensino superior brasileiro tenham uma compreensão das contribuições que esses cursos trazem para esses profissionais estrangeiros e para seus países, no caso da saúde, a contribuição é ampliada para a melhoria da Saúde Global.

Por fim, ressaltamos que, para além dos acordos internacionais de cooperação, somente a prática cotidiana docente que aponta as reais dificuldades para o sucesso dos cursos. Nesse sentido, destacamos que a análise histórica dos processos mostra entraves de diversas naturezas que foram superadas, em maior ou menor medida, pelo empenho dos docentes e coordenadores. Uma das questões relevantes é a falta de estrutura relativa à internet, o que dificulta acesso à literatura, bem como o relacionamento à distância com os orientadores. O aprendizado na superação dessa dificuldade contribuiu de forma significativa para os investimentos na política de ciência aberta da Fiocruz.

\section{Referências}

ALMEIDA, C. et al A concepção brasileira de "cooperação Sul-Sul estruturante em saúde". Revista Eletrônica de Comunicação, Informação \& Inovação em Saúde, Rio de Janeiro, vol. 4, n. 1, p. 25-35, 2010. Disponível em: 〈https://goo.gl/6ReTJf〉. Acesso em: 21 nov. 2017.

ARTMANN, E. Mestrado em Saúde Pública de Angola: desafios na construção de respostas às demandas de saúde. In: I Seminário Angola-Brasil de Saúde Pública: Resumo das dissertações dos egressos do mestrado em Saúde Pública de Angola. Rio de Janeiro: ENSP, 2012. p. 7-8. Disponível em: <https://goo.gl/9AiAbK>. Acesso em: 21 nov. 2017. 
Abreu e Guilam / Trajetórias profissionais de egressos de mestrados por meio da Cooperação Estruturante em Saúde

BUSS, P. Brazil: structuring cooperation for health. The Lancet, London, v. 377, n. 9779, p. 1722-3, 2011. Disponível em: <https://goo.gl/Zfw231>. Acesso em: 21 nov. 2017.

CAMPOS, R. P. et al. Rumo a uma metodologia para o estudo de boas práticas em cooperação internacional em saúde. Revista Eletrônica de Comunicação, Informação \& Inovação em Saúde, Rio de Janeiro, vol. 4, n. 1, 2010. Disponível em: < https://goo.gl/WRFsyb >. Acesso em: 21 nov. 2017.

FUNDAÇÃO OSWALDO CRUZ. Centro de Relações Internacionais em Saúde. Crisinforma, Rio de Janeiro, n. 1, p. 1, set. 2012. Disponível: <https://goo.gl/N3HfwD>. Acesso em: 21 nov. 2017.

GIL, A. Métodos e técnicas de pesquisa social. São Paulo: Atlas, 2008.

GOMES, M. H. A.; GOLDENBERG, P. Retrato quase sem retoques dos egressos dos programas de pós-graduação em Saúde Coletiva, 1998-2007. Ciência \& Saúde Coletiva, Rio de Janeiro, v. 15, n. 4, p. 1989-2005, 2010. Disponível: 〈https://goo.gl/1s9XGi〉. Acesso em: 21 nov. 2017.

HORTALE, V. A. et al. Características e limites do mestrado profissional na área da Saúde: estudo com egressos da Fundação Oswaldo Cruz. Ciência \& Saúde Coletiva, Rio de Janeiro, v. 15, n. 4, p. 1989-2005, 2010. Disponível em: 〈https://goo.gl/NS6pZP〉. Acesso em: 21 nov. 2017.

HORTALE, V. A. et al. Trajetória profissional de egressos de cursos de doutorado nas áreas da saúde e biociências. Revista de Saúde Pública, São Paulo, v. 48, n. 1, p. 1-9, 2014. Disponível em: <https://goo.gl/NS6pZP> Acesso em: 21 nov. 2017.

KELLERMAN, R. et al. Investing in African research training institutions creates sustainable capacity for Africa: the case of the University of the Witwatersrand School of Public Health masters programme in epidemiology and biostatistics. Health Research Policy and Systems, London, v. 10, p. 1-7, 2012. Disponível em: <https://goo.gl/x1vHCM>. Acesso em: 21 nov. 2017.

KLAVEREN, M. V. et al. Visão geral do trabalho e emprego das mulheres em Angola: Projecto Decisões para Toda a Vida relativo ao ODM3. Relatório Nacional $n^{\circ} 2$. Universidade de Amesterdão, 2009. Disponível: 〈https://goo.gl/JKK7Ce〉. Acesso em: 21 nov. 2017.

LAKATOS, E. M.; MARCONI, M. A. Fundamentos de metodologia científica: técnicas de pesquisa. 7. ed. São Paulo: Atlas, 2010. 
Abreu e Guilam / Trajetórias profissionais de egressos de mestrados por meio da Cooperação Estruturante em Saúde

LEITE, A.; CARMO, V. Os doutorados em Cotutela no Brasil e em seus principais parceiros acadêmicos. Revista Brasileira de Pós-Graduação, Brasília, DF, v. 11, n. 26, p. 969-997, 2014. Disponível em: <https://goo.gl/Lom929>. Acesso em: 21 nov. 2017.

PASQUALIN, L. O. A Cooperação internacional da Fiocruz na formação de recursos humanos em saúde: os programas de pós-graduação. 2014. Dissertação (Mestrado Profissional em Saúde Pública) - Escola Nacional de Saúde Pública Sérgio Arouca, Rio de Janeiro, 2014. Disponível em: <https://goo.gl/s1gjbm> Acesso em: 21 nov. 2017.

PEZZOLI, L. et al. Time, place, and people: composition of the EPIET Alumni Network and its contribution to the European public health resource in 2013. Epidemiology and Infection Journal, v. 143, n. 12, p. 2539-2546, 2015. Disponível em: 〈https://goo.g1/RBuUet>. Acesso em: 21 nov. 2017.

TELLES, J. Escritório Regional da Fiocruz em África e as Ações Estratégicas de Cooperação Estruturante em Saúde: relatório apresentado à Presidência da Fiocruz. Rio de Janeiro: Fiocruz, 2014.

Recebido em 16/05/2017

Aprovado em 17/11/2017 